NOTICE: this is the author's version of a work that was accepted for publication in the International Journal of Drug Policy. Changes resulting from the publishing process, such as peer review, editing, corrections, structural formatting, and other quality control mechanisms may not be reflected in this document. Changes may have been made to this work since it was submitted for publication. A definitive version was subsequently published in the International Journal of Drug Policy, Vol. 24 (2013). DOI:

10.1016/j.drugpo.2012.12.002 
Kronic Hysteria: Exploring the intersection between Australian synthetic cannabis legislation, the media, and drug-related harm

Stephen J. Bright ${ }^{1,2}$, Brian Bishop ${ }^{1}$, Robert Kane ${ }^{1}$, Ali Marsh ${ }^{1} \&$ Monica J. Barratt ${ }^{3}$

1. School of Psychology and Speech Pathology, Curtin University, Perth, Western Australia

2. Peninsula Health, Frankston, Victoria

3. National Drug Research Institute, Curtin University, Melbourne, Victoria

Corresponding author: Stephen J. Bright

School of Psychology and Speech Pathology, Curtin University

GPO Box U1987, Perth WA 6845, Australia

Telephone: +61 419143773

Facsimile: +61 892667279

Email: s.bright@curtin.edu.au 


\title{
Kronic Hysteria: Exploring the intersection between Australian synthetic cannabis legislation, the media, and drug-related harm
}

\begin{abstract}
Background: Having first appeared in Europe, synthetic cannabis emerged as a drug of concern in Australia during 2011. Kronic is the most well-known brand of synthetic cannabis in Australia and received significant media attention. Policy responses were reactive and piecemeal between state and federal governments. In this paper we explore the relationship between media reports, policy responses, and drug-related harm.

Methods: Google search engine applications were used to produce time-trend graphs detailing the volume of media stories being published online about synthetic cannabis and Kronic, and also the amount of traffic searching for these terms. A discursive analysis was then conducted on those media reports that were identified by Google as 'key stories'. The timing of related media stories was also compared with self-reported awareness and month of first use, using previously-unpublished data from a purposive sample of Australian synthetic cannabis users.
\end{abstract}

Results: Between April and June 2011, mentions of Kronic in the media increased. The number of media stories published online connected strongly with Google searches for the term Kronic. These stories were necessarily framed within dominant discourses that served to construct synthetic cannabis as pathogenic and created a 'moral panic'. Australian state and federal governments reacted to this moral panic by banning individual synthetic cannabinoid agonists. Manufacturers subsequently released new synthetic blends that they claimed contained new unscheduled chemicals.

Conclusion: Policies implemented within in the context of 'moral panic', while wellintended, can result in increased awareness of the banned product and the use of new yet-tobe-scheduled drugs with unknown potential for harm. Consideration of regulatory models should be based on careful examination of the likely intended and unintended consequences. Such deliberation might be limited by the discursive landscape.

Key words: Discourse, Emergent Drug Trends, Internet, Policy, Synthetic Cannabis 


\section{Kronic Hysteria: Exploring the intersection between Australian synthetic cannabis}

legislation, the media, and drug-related harm

Synthetic cannabis refers to products containing a herbal mixture that is then sprayed with synthetic cannabinoid agonists (Dargan, Hudson, Ramsey, \& Wood, 2011; Dresen et al., 2010; Schifano et al., 2009). Synthetic cannabis first emerged in Europe in 2004 with reports of a product called Spice producing effects that were very similar to cannabis, such as euphoria, increased sociability, relaxation, increased appetite, and sometimes anxiety and paranoia (Castellanos, Singh, Thornton, Avila, \& Moreno, 2011; Psychonaut Web Mapping Research Group, 2009). These marked psychoactive effects were unlikely to have been produced by the largely inert herbal materials that Spice was purported to contain, which included: Althaea officinalis (Marshmallow), Canavalia maritima (Beach bean), Leonotis leonurus (Wild dagga), Leonotis sibericus (Siberian motherwort), Nelumbo nucifera (Pink lotus), Nymphaea caerulea (Blue lotus), Pedicularis densiflora (Indian warrior), Rosa cania (Dog rose), Scutellaria nana (Dwarf Skullcap), and Zornia latifolia (Maconha brava) (Psychonaut Web Mapping Research Group, 2009).

An analysis of Spice (Auwärter et al., 2009; Lindigkeit et al., 2009) revealed that it contained a range of synthetic cannabinoid agonists. These chemicals included a homologue of $\mathrm{CP}$ 47,497, which within the Australian Criminal Code Act of 1995, is considered an analogue of delta-9-tetrahydrocannabinol $\left(\Delta^{9}\right.$-THC) based on the similarity of its structure to $\Delta^{9}$-THC. As such, possession of this product was a breach of federal law. However, outside of federal jurisdictions (e.g., airports, border control and universities), in those Australian states without analogues clauses within their drug acts, products containing this chemical were legal.

JWH-018, or 1-Pentyl-3-(1-naphthoyl) indole, is another synthetic cannabinoid agonist that was identified to be present in Spice (Auwärter et al., 2009; Lindigkeit et al., 2009). JWH is an abbreviation for John W. Huffman, the individual who first synthesised these cannabinoid agonists. Later analyses have revealed a range of JWH's chemicals present in synthetic cannabis products including: JWH-019, JWH-022, JWH-073, JWH-122, JWH-250, \& JWH398 (de Jager, Warner, Henman, Ferguson, \& Hall, 2012; Fattore \& Fratta, 2011; Hastie, 2011). These chemicals were structurally dissimilar from $\Delta^{9}$-THC and other scheduled cannabinoid agonists, and thus were not considered analogues within the Australian Criminal 
Code Act of 1995. Consequently, prior to legislative changes in 2011, products containing these chemicals were legal to supply and possess in all Australian states and territories.

While anecdotal reports of synthetic cannabinoid use in Australia date back to 2005, it was in 2011 that synthetic cannabis emerged as a drug of concern in Australia. Kronic has been the most well-known brand of synthetic cannabis in Australia with various blends produced, including Skunk, Purple Haze, Tropical, Pineapple Express, and Black Label. In April 2011, radio and tabloid newspapers first began reporting on the use of Kronic at Western Australian (WA) mine sites as a means of evading drug testing (Macdonald, 2011). Media interest swiftly grew, and by June the WA government moved to schedule seven synthetic cannabinoid agonists: JWH-018, JWH-073, JWH-122, JWH-200, JWH-250, CP 47,497, and the C8 Homologue of CP 47,497 (Misuse of Drugs (Amounts of Prohibited Drugs) Order (No. 2) 2011, Western Australia).

Within days, new synthetic cannabis blends appeared that claimed to contain new unscheduled synthetic cannabinoid agonists. For example, Kronic released its 'Black Label' blend specifically for its WA customers. This is consistent with the experience in the UK (Dargan et al., 2011) and the USA (Shanks, Dahn, Behonick, \& Terrell, 2012) where analysis of synthetic cannabis blends available after bans found the presence of a range of new chemicals. De Jager et al. (2012) have reported that blends of Kronic purchased after bans in Australia contained chemicals previously unknown to them that were later revealed via mass spectra to be JWH-022 and AM2201.

Then in August 2011, the media reported on a Perth man with a pre-existing heart condition who had a heart attack. While this event is not something the media would normally report on, the man had allegedly been smoking Kronic Black Label prior to his death (Phillips, 2011). In a response to this alleged first 'Kronic-related death', the WA government scheduled 14 more cannabinoid agonists (Poisons (Appendix A Amendment) Order (No. 2) 2011). Again, new blends appeared that claimed to contain new unscheduled chemicals.

Other Australian states followed WA's lead. South Australia outlawed 17 cannabinoid agonists (Trans-Tasman Mutual Recognition (South Australia) Variation Regulations 2011, South Australia). In addition to the seven cannabinoid agonists that WA banned, the New South Wales government banned AM-694 (Drug Misuse and Trafficking Act 1985, New South Wales). Tasmania outlawed four cannabinoid agonists (CP 47,497, JWH-018, JWH- 
073, and JWH-250), and also introduced an analogues clause into their Misuse of Drugs Acts (Misuse of Drugs Order 2011 (S.R. 2011, No. 74) - Reg 4, Tasmania). The Northern Territory banned 18 synthetic cannabinoid agonists (Misuse of drugs amendment (synthetic cannabinoids) regulations 2011 (No 33 of 2011), Northern Territory), while the Queensland government has proposed banning a total of 22 cannabinoid agonists and redefining the definition of what is considered a dangerous drug (Criminal and Other Legislation Amendment Bill 2011, Queensland; Drugs Misuse Amendment Regulation (No. 1) 2011, Queensland; Drugs Misuse Amendment Regulation (No. 2) 2011, Queensland). The new definition states that a dangerous drug includes anything that is intended to "have a substantially similar pharmacological effect" to an illicit substance (Criminal and Other Legislation Amendment Bill, 2011).

The Australian Therapeutic Goods Agency (TGA, 2011) received a request from the WA government to review the status of synthetic cannabinoid agonists, and subsequently scheduled eight cannabinoid agonists in July 2011. This made their possession a federal offence. Most Australian state drug acts refer to the Standard for the Uniform Scheduling of Medicines and Poisons (SUSMP) or Poisons Standard 2011, which is the legislative instrument over which the TGA has authority (The Standard for the Uniform Scheduling of Medicines and Poisons (SUSMP) also known as the Poisons Standard 2011, Australia). Consequently, products containing any of these eight cannabinoid agonists were by default illegal in states that had not specifically scheduled these chemicals.

It might be suggested that the Australian legislative response to synthetic cannabis has been reactive and piecemeal rather than evidence-based. Some have suggested that banning each chemical as it emerges is like a dog chasing its own tail (Fattore \& Fratta, 2011). Other commentators have described this approach to legislation as a merry-go-round-as one new drug gets discovered and banned, another one emerges purporting to be 'legal' (Dargan et al., 2011; Evans-Brown, Bellis, \& McVeigh, 2011; Measham, Moore, Newcombe, \& Welch, 2010). So why has Australia's legislative response to synthetic cannabis not been evidencebased?

It is possible that media reports concerning synthetic cannabis created a moral panic that contributed to a legislative reaction. Early descriptions of moral panic, such as Cohen's (1972) analysis of "Mods" and "Rockers" in the UK, have noted that moral panic first 
involves a person, group, episode, or situation being framed by the media as a threat to society. Sometimes the moral panic quickly dissipates, while other moral panics reach critical mass with significant and long lasting repercussions, such as changes in policy. In this respect, Brosius and Weimann (1996) have suggested that the media sets the agenda for policy debate.

McArthur (1999, p. 151) has stated that the media "shape[s] not only the public profile of [drug] problems but also the political response to them". Forsyth (2012) has proposed that once media reports concerning the emergence of a new drug break in the mainstream press, they will draw on the 'drug scare' narrative that constructs the new drug as dangerous and the need for urgent action. In turn, a media campaign against the drug develops that recruits politicians, researchers and the morally righteous. The subsequent moral panic leads to a perception that urgent legislative action is required and is likely to result in policy that is reactive rather than responsive.

Moral panic occurs within the context of the dominant discourses that exist within a society. For example, Cohen (1972) stated that "by thrusting certain moral directives into the universe of discourse" the media can create drug problems "suddenly and dramatically" (p. 10). Dominant discourses are linguistic frameworks inherent to any given culture that develop in symbiotic relationships with those institutions with power (Burr, 2003). They constrain what can be rationally said, written, and thought about drugs. Each discourse provides specific subject positions that demarcate the narratives that are coherent within the discourse (Burr, 2003). These narratives, such as the 'drug scare narrative', are perceived by individuals within the culture from which the dominant discourse emanates to hold the most 'truth' value. Nonetheless, there are competing dominant discourses with some being more privileged than others, and it is in the interest of any given institution to promote those discourses that maintain the institution's version of reality as 'truth' since this provides the institution with power.

Bright, Marsh, Bishop and Smith (2008) undertook an analysis of the dominant discourses within Australia that frame Alcohol and Other Drugs (AOD). They examined newspaper reports of AOD over a 12 month period, and then triangulated this analysis with a sample of newspaper reports from five years prior and a televised debate on AOD. Bright et al. (2008) determined that in Australia, six dominant discourses framed AOD-related issues: medical, 
moral, legal, political, economic, and glamour (see Table 1). Within medical discourse, for example, drug use is often pathologised such that drug users are sick. This limits the degree to which 'recreational drug use' can be considered since any drug use is defined as inherently unhealthy. Within this discourse, experts are afforded a subject position that has significant authority and typically support the pathogenic narrative. Further, since medical discourse is paternal, the pathogenic narrative supports prohibition-based drug policy.

\section{[Insert Table 1 about here]}

The methodology used by Bright et al. (2008) might not be appropriate for understanding the discourses that framed the emergence of synthetic cannabis in Australia given its rapid emergence and the subsequent constant flux. Rather, methodologies that have explored the rapid emergence of new drugs might have more utility. In this journal, Forsyth (2012) has recently described the phenomena of the 'drug scare' using the UK experience with Mephedrone as a case study. He proposed that media reports about the emergence of a new drug that are fuelled by 'moral panic' are unhelpful since they might divert attention from other more significant public health concerns (e.g., alcohol, diabetes, cardiovascular disease, cancer, etc.), and also provide free advertising through creating increased public awareness of the drug. Through examining online media, Forsyth was able to demonstrate that interest in buying mephedrone increased following sensationalist media coverage.

The present study draws from Forsyth's (2012) methodology using Australian online media and self-reports from a sample of Australian synthetic cannabis users to understand how synthetic cannabis emerged as a drug of concern in 2011. In doing so, we aim to explore how the media, legislative change, and drug-related harm intersect. Discursive analysis was used to help disentangle this complex intersection. Such analysis is particularly useful here given the dynamic and rapid social changes that occurred in 2011, since it allows for subjective interpretations of the available anecdotal evidence given limited empirical data.

\section{Method}

Drawing from Forsyth's (2012) methodology, Google Trends was first used to produce timetrend graphs detailing the number of stories being published online about synthetic cannabis and Kronic, and also the amount of traffic searching for these terms. Google Trends also generates links to media reports at key milestones. Forsyth has noted some limitations in 
using this application since Google is not the only search engine; however, it is the most widely used. Further, Google Trends are normalised so the graphs do not represent the absolute number of searches conducted or the number of media stories. Additionally, the media volume reported is dependent on the parameters that Google uses to determine if text is a 'news story'.

It is reasonable to assume that the ways in which the Australian online media was able to frame the emergence of synthetic cannabis was limited by the available dominant discourses. As such, the discourse and narratives were examined within the key reports generated by Google Trends. This examination was conducted by the first author (SB). It was iterative and involved consideration of the various subject positions that were available within the text, in addition to the way in which synthetic cannabis was constructed. As each discourse emerged, it was considered within the context of the institutions that support and maintain the discourse. Finally, the discourse was considered within the context of Bright et al.'s (2008) delineation of the dominant discourses available for AODs in Australia.

To ensure credibility (Lietz, 2010), the data were triangulated with radio media. Two episodes of the Australian Broadcasting Commission's (ABC) Triple J show "Hack" that reported on synthetic cannabis were analysed. The first show, entitled "Cheating workplace drug tests”, aired on May 10 (Quartermaine, Tilley, Barrington, \& Sawrey, 2011). The second show was entitled "National Kronic ban" and aired on July 7 (Tilley \& Sawrey, 2011). Purposeful sampling of media reports and social media was also conducted to reconstruct a timeline of the emergence of, and response to, synthetic cannabis. In addition, thick descriptions were provided of each text that used direct quotes to ensure that the analysis stayed true to the original text.

Rigour was ensured through an audit trail that documented the analysis and the reasoning that underpinned the emergent discourses (Morse, 1994). Thoughtful consideration of the discursive researcher's (SB) standpoint and opinions was documented in the audit trail to ensure reflexivity. This can be summarised in the following disclosure statement:

I dislike paternalism since I value freedom of choice and believe that drug users can rationally weigh up the pros and cons of drug use in the context of the available evidence regarding harm. I believe that drug 
policy is rarely developed in the context of the available evidence and is often reactive in nature.

By including this statement, we acknowledge that it is impossible for the researcher to be 'objective' or 'neutral' in the production of knowledge. Subjectivity, while once seen as negative or as bias to be eliminated, can be used as a fruitful path to greater understanding of the subject matter and our role in its construction. Instead, readers should interpret our paper with knowledge of the discursive researcher's positioning as stated above.

Finally, two pieces of previously-unpublished data were included in this paper from a study by the final author and colleagues (Barratt, Cakic \& Lenton, in press): (a) month and year of first use of synthetic cannabis, and (b) where synthetic cannabis users first reported hearing about the drug. A purposive sample of 316 Australian synthetic cannabis users answered these questions as part of an online survey. A description of the sample and the survey methodology has been published elsewhere (Barratt et al., in press).

\section{Findings and Discussion}

Figures 1 and 2 contain graphs produced using Google Trend. The lower line in each figure depicts the volume of media stories being published online that referred to Kronic and synthetic cannabis respectively. The upper line in each figure indicates how many people were searching for "Kronic" and "synthetic cannabis". As can be seen in Figures 1 and 2, the first online media stories about synthetic cannabis and Kronic began to emerge in March, with a sharp increase in the number of stories in May and June.

The first key story concerning Kronic was from The Age on June 8 (indicated by 'A' in Figure 1) and was entitled "Roadtesting Kronic: Is fake grass worth the hype?". This 'gonzo journalism' piece describes the author's experience of smoking Kronic and is framed within neo-liberal and economic discourse. For example, the author states that "so many people were having fun with [Kronic] that the anti-fun brigade had no choice but to swing into action" and compared the effects of Kronic to "two glasses of champagne". Bright et al. (2008) note that within the dominant Australian discursive landscape, only alcohol, tobacco, and caffeine can typically be framed within economic discourse, which means that this story is framed outside of the dominant discourses. 


\section{[Insert Figure $1 \& 2$ about here]}

Similarly, the individuals who were interviewed as part of the first radio report on Kronic in May (Quartermaine et al., 2011) framed their use of Kronic outside of dominant discourses. Again, use of Kronic was framed within neo-liberal and economic discourse. For example, interviewees stated how they made an informed choice to use Kronic in which the harms associated with failing a drug test outweighed the unknown harms associated with using chemicals with little to no toxicology data. Further, they described responsible use of Kronic, such as not using it before or during work, which also falls outside of the dominant discourses.

Such initial framing was possible without widespread concern regarding synthetic cannabis and is consistent with Forsyth's (2012, p. 198) observation that initial reports regarding a new drug are generally published in alternative publications such as music press (e.g., Triple $J$ Radio) "or equivalent specialist sections of mainstream titles" (e.g., The Age). For example, in the UK a report preceding the moral panic regarding Mephedrone appeared in the Telegraph by a prominent medical personality entitled "I took Mephedrone and I liked it" (Pemberton, 2010). Despite being situated outside of the dominant discursive frameworks, such early stories increase the public's awareness and might provide an advertisement for the emergent drug. Indeed, as can be seen from the upper line in Figure 1, the number of Australian's searching for Kronic on Google began increasing significantly around this time. It is interesting to note that "Kronic" was more searched than "synthetic cannabis", perhaps highlighting the effect that the media had on 'branding' synthetic cannabis. This is similar to the way in which MDMA was branded as Ecstasy in the early 1980's, perhaps since the latter term created additional public interest and may have contributed to the moral panic that precipitated the prohibition of MDMA in the USA (Eisner, 1989).

The increased awareness also provides an impetus for a 'moral panic', with subsequent stories framed within the dominant discourses. The second key story concerning Kronic was published by the Sydney Morning Herald on 16 June and was entitled "WA becomes first state with Kronic ban" (see "B" in Figure 1). Interestingly, the first and only relevant key story concerning synthetic cannabis was also about legislative change - this time the South Australian government's intention to ban synthetic cannabis (see "A" in Figure 2). Both 
stories were framed within dominant discourses. Specifically, they were framed within legal, medical and moral discourse.

Within medical discourse synthetic cannabis was constructed as a pathogen with similar (or greater) dangers to cannabis. Such constructions were typically reinforced by experts attesting to these dangers. Within this discursive framework, primacy is given to those individuals assuming the subject position of expert. This subject position is highly regarded in contemporary society, and might be considered to have subsumed the role of the priest as the figure of authority. Like the priest, the information provided by a medical expert is not necessarily 'true' despite it being perceived as holding the greatest 'truth' value. Indeed, there are often little to no toxicity data for most emergent drugs. For example, Forsyth (2012) noted that it was the news of a Mephedrone-related death that was later found to be false, which provided the impetus for the UK government to refer the matter to the Advisory Council on the Misuse of Drugs.

Similarly, the second ABC radio show that aired in July focused on the national legislative changes. Here, the federal secretary for health assumed the subject position of expert. From this position she was able to authoritatively declare that synthetic cannabis is "just not safe", causing hallucinations and heart palpitations. While there have been increasing reports of synthetic cannabis harms, a recent survey of 316 Australian community-based synthetic cannabis users found that while such effects were reported by around one third of the sample, very few respondents reported that their symptoms were serious enough to seek help and many respondents did not report experiencing these harms (Barratt et al., in press). Barratt et al.'s (in press) survey results also indicate that a desire to use a legal recreational drug was one of the main reasons for first trying synthetic cannabis. Consistent with medical discourse, there was no available subject position for recreational drug users with the secretary stating that there "is no therapeutic reason to be using [synthetic cannabinoid agonists] and that's why they've been banned".

Within moral discourse, users assume the subject position of an irresponsible deviant. For example, the South Australian Attorney-General expressed a concern that "users are driving under the influence, posing a serious danger to themselves and others". Such constructions, alongside the pathogenic narrative available within medical discourse, indicate a need for 
urgent legislative intervention. In turn, these discourses provided a fertile environment for 'moral panic'.

This moral panic is likely to have contributed to the first wave of bans that occurred in June and July of 2011 since Australian governments had a moral imperative to take urgent legislative action. Such urgent action was naturally reactive and led to a number of bans placed on individual synthetic cannabinoid agonists. Although authorities may be wellintentioned as they prohibit emerging drugs like synthetic cannabinoid agonists, the unintended consequences of these policies may have increased harm to some users since the reporting of each scheduling decision creates increased awareness. Such increased awareness could lead to increased use of synthetic cannabis.

Indeed, as can seen be from the lower lines in Figures 1 and 2, online media interest first increased in the lead up to the first wave of bans in June and July. There was also an increase in the number of Australians searching for "Kronic" and "synthetic cannabis", as indicated by the lower lines in Figures 1 and 2, which tracks in relative accordance with the increased volume in media. It is reasonable to assume that many of these individuals would not have previously been aware of synthetic cannabis. The first hit for a Google search for 'Kronic to be banned' that we conducted in June was an Australian-based online Kronic shop, and Google advertisements at the end of many commercial online media reports were for online shops selling synthetic cannabis. Kronic could not have asked for better advertising. For example, Green (2011) reported on a man who "saw [Kronic] on the news and thought... holy smoke, I'm going to order this".

Barratt et al.'s (in press) survey collected as-yet-unpublished data on the month that respondents first used synthetic cannabis. Reported in Figure 3, this data appear to be indicative of two distinct cohorts of Australians who initiated synthetic cannabis use in 2011: (i) those whose initial use preceded media reporting, and (ii) those who initiated use at around the same time as reports about Kronic peaked in the media. A statistical analysis of the data indicated that those who used synthetic cannabis for the first time in 2011 or 2012, which was when media interest began to heighten, were also significantly more likely to have reported to have heard about it through the media, whereas those used synthetic cannabis for the first time before 2011 were significantly more likely to have heard about it through other means (e.g., social media, friends, vendors, etc.), $\left.\chi^{2}(1, \mathrm{~N}=273)=15.7\right) p<0.001$. 
In the lead up to the bans, people reportedly tried to stockpile Kronic (Rickard, 2011), and Kronic manufacturers endeavoured to sell any remaining stock. Kronic distributors used social media, especially Facebook and Twitter, to engage their customers. These technologies provided a unique way of monitoring drug-related social interactions in real-time. For example, a post on the Kronic Facebook page from June reads:

we only found out about the ban today so just clearing out the last of our stock. It has to be gone by 2 mmorow close of business so we have 2 options... give heaps away for free or just dispose of it tomorrow. I know what we'd prefer!

Hundreds of Facebook users 'liked' and commented on this and other posts. For example, 'James' stated “I want some, no money but I've already bought heaps from yas [sic] so give me it for free".

The announcement by the WA government to ban seven synthetic cannabinoid agonists also led to a "smoke "em party" that was shut down by police as a matter of public safety. The party was moved to another venue, but then cancelled following further police intervention (“Kronic Party Plans up in Smoke”, 2011).

The next key Kronic story according to Google Trends was published in The Brisbane Times on June 30. Entitled "NZ importer admits Kronic contaminated", this story describes the findings from an analysis of Kronic conducted by the New Zealand governments that found traces of a novel benzodiazepine. This story was primarily framed within medical discourse, with the incident constructed as a "contamination".

Just days after the WA government banned seven synthetic cannabinoid agonists, new products were released that claimed to circumvent the legislative changes. One such product was Kronic "Black Label”. The final key Kronic-related story, which was published on August 5 in The Australian, described how a man who was "believed" to have been smoking Kronic "Black Label" was rushed to hospital after "suffering a suspected heart attack". He later died. Entitled "WA police query banned drug Kronic link to man's death", this story was framed within medical and legal discourse. Again, the potential harms associated with Kronic indicated an urgent need for legislative intervention. In response to this death, the WA government banned an additional 14 cannabinoid agonists (Poisons (Appendix A 
Amendment) Order (No. 2) 2011, Western Australia). Again, media interest and internet traffic searching for "Kronic" and "synthetic cannabis" increased in the lead up to these bans, as can be seen in Figure 1 and 2.

\section{Conclusions}

By examining the emergence of synthetic cannabis as a drug of concern in Australia, the present paper aimed to help understand how the media, legislative change, and drug-related harm intersect. The notion of dominant discourses was proposed to be helpful in understanding this relationship since they will demarcate how the media constructs the emergence of a new drug, how policy makers are able to frame the debate, and in turn, people's drug using behaviour.

The pre-existing Australian dominant discourses, as outlined by Bright et al. (2008), appear to have led to the construction of synthetic cannabis as a dangerous pathogen. This construction may have contributed to a 'moral panic'. The moral panic appears to have been fuelled by experts highlighting the potential dangers of the new drug. Whilst such claims are presumably intended to reduce the likelihood of people using these substances, they might not be completely accurate given an absence of toxicological data and do not appear to be a deterrent. For example, Forsyth (2012) found that the most significant increases in interest in purchasing Mephedrone occurred following each report of an alleged Mephedrone-related death. A similar trend has been reported by Dasgupta, Mandl and Brwonstien (2009), who found that the number of overdoses from prescription opiates increased significantly two to six months after major stories concerning prescription opiates broke in the media.

Given the truth value of these expert statements within the dominant discourse, governments have a moral imperative to ban the new drug. This can lead to reactive polices that may have a negative impact on drug-related harm since: (i) further awareness is created which could increase harm as more individuals try synthetic cannabis, and (ii) once banned, newer, lessunderstood psychoactive products enter the market to replace the banned drug. Thus, while the availability of the newly illegal drug decreases following prohibition, other similar drugs with unknown health harms become more available in their place. Even if the new products do not contain new legal chemicals, and in fact contain recently scheduled chemicals, consumers are then at heightened risk of prosecution for possession of a product they believed to be legal. The possession of synthetic cannabinoid agonists could be treated more 
severely than the possession of cannabis in Australia since individuals charged with possession of synthetic cannabinoid agonists might not be eligible to participate in cannabis diversion schemes.

An alternative approach would have been to have regulated this market. Regulation would mandate the provision of accurate information, purity and strength. There is currently a disincentive for companies to provide information to potential users about the active ingredients or about safer ways to consume synthetic cannabis. To avoid litigation, most brands of synthetic cannabis state that they are "not for human consumption", misrepresent what they contain, or provide obscure instructions for use. For example, a packet of Kronic's Pineapple Express stated that it "contains a unique blend of all natural organic extracts" and it "emits a pleasant, relaxing smoke when burned". The lack of quality control is evident in the recall of this particular brand of Kronic due to it accidentally containing a novel benzodiazepine (Couch \& Madhavaram, 2012).

Restrictions on where and to whom synthetic cannabis could be sold would also be easier to manage in a regulated environment. Some (e.g., Evans-Brown et al., 2011; Hughes \& Winstock, in press) suggest that emerging psychoactive substances be regulated as medicinal products as a pragmatic compromise to the current, arguably unsustainable, approach. We believe Australia should also consider alternative models of regulation, based on careful examination of the likely intended and unintended consequences. The recently regulatory scheme proposed by the New Zealand government provides an example of such alternative models (Office of the Associate Minister of Health, 2012). It will be interesting to see how this new model affects the synthetic cannabis market and drug-related harm.

Evidence-based policy development must consider a psychoactive substance within the complex interrelationships between state and federal legislation, media reporting and dynamic webs of supply and demand. The unpredicted and unintended outcomes of drug policy typically result from inadequete consideration of these factors. For example, workplace drug testing is a well-intentioned policy that aims to reduce drug-related harm, but has had the unintended effect of producing a market for synthetic cannabis as a substitute for cannabis which, until recently, was unable to be detected by workplace drug testing technologies. 
However, it is unlikely that Australia's response to synthetic cannabis will consider alternative models of regulation. In May 2012, eight broad chemical groups were scheduled by the TGA: Benzoylindoles, Cyclohexylphenols, Dibenzopyrans, Naphthoylindoles, Naphthylmethylindoles, Naphthoylpyrroles, Naphthylmethylindenes, and Phenylacetylindoles (TGA, 2012). In addition, they scheduled "synthetic cannabinomimetics", though no definition of this term has been provided. Only time will tell what effects (both intended and unintended) this latest legislative actions will have on drugrelated harm.

\section{References}

Auwärter, V., Dresen, S., Weinmann, W., Müller, M., Pütz, M., \& Ferreirós, N. (2009). 'Spice' and other herbal blends: Harmless incense or cannabinoid designer drugs? Journal of Mass Spectrometry, 44, 832-837.

Barratt, M., Cakic, V., \& Lenton, S. (in press). Patterns of synthetic cannabinoid use in Australia. Drug and Alcohol Review.

Bright, S. J., Marsh, A., Bishop, B., \& Smith, L. M. (2008). What can we say about substance use? Dominant discourses and narratives emergent from Australian media. Addiction Research \& Theory, 16, 135-148.

Brosius, H.B., \& Weimann, G. (1996). Who sets the agenda? Agenda setting as a two step flow. Communication Research, 23, 561-580.

Burr, V. (2003). Social constructionism ( $2^{\text {nd }}$ ed.). London: Routledge.

Castellanos, D., Singh, S., Thornton, G., Avila, M., \& Moreno A. (2011). Synthetic cannabinoid use: A case series of adolescents. Journal of Adolescent Health, 49, 347349.

Cohen, S. (1972). Folk Devils and Moral Panics. London: MacGibbon and Kee.

Couch, R A. F., \& Madhavaram, H. (2012). Phenazepam and cannabinomimetics sold as herbal highs in New Zealand. Drug Testing and Analysis, 4, 409-414. 
Criminal and Other Legislation Amendment Bill 2011, Queensland. Retrived August 1, from Statute on internet. Available at:

http://www.legislation.qld.gov.au/Bills/53PDF/2011/CriminalOLAB11.pdf

Criminal Code Act, 1995, Australia.

Dargan, P.I., Hudson, S., Ramsey, J., \& Wood, D.M. (2011). The impact of changes in UK classification of the synthetic cannabinoid receptor agonists in 'Spice'. International Journal of Drug Policy, 22, 274-277.

Dasgupta, N., Mandl, K. D., \& Brownstein, J. S. (2009). Breaking the News or Fueling the Epidemic? Temporal Association between News Media Report Volume and OpioidRelated Mortality PLoS ONE, 4, (11). doi: 10.1371/journal.pone.0007758

de Jager, A. D., Warner, J. V., Henman, M., Ferguson, W., \& Hall, A. (2012). LC-MS/MS method for the quantitation of metabolites of eight commonly-used synthetic cannabinoids in human urine - An Australian perspective. Journal of Chromatography B, 897, 22- 31 .

Drug Misuse and Trafficking Act 1985, New South Wales.

Drugs Misuse Amendment Regulation (No. 1) 2011, Queensland.

Drugs Misuse Amendment Regulation (No. 2) 2011, Queensland.

Dresen, S., Ferreirós, N., Pütz, M., Westphal, F., Zimmermann, R., \& Auwärter, V. (2010). Monitoring of herbal mixtures potentially containing synthetic cannabinoids as psychoactive compounds. Journal of Mass Spectrometry, 45, 1186-94.

Eisner, B. (1989). Ecstasy: The MDMA story. Berkeley: Ronin.

Evans-Brown, M., Bellis, M. A., \& McVeigh, J. (2011). Should "legal highs" be regulated as medicinal products? BMJ: British Medical Journal, 342. doi: 10.1136/bmj.d1101

Fattore, L., \& Fratta, W. (2011). Beyond THC: the new generation of cannabinoid designer drugs. Frontiers in Behavioral Neuroscience. 5, Article 60.

Forsyth, A. J. M. (2012). Virtually a drug scare: Mephedrone and the impact of the Internet on drug news transmission. International Journal of Drug Policy, 23, 198-209. 
Green, S. (2011, November 18). Kronic made me 'bloody useless'. Retrieved from http://m.cqnews.com.au/story/2011/11/18/kronic-made-me-bloody-useless

Hastie, H. (2011). WA 'Kronicles’ detection of synthetic cannabinoids. Science Network Western Australia. 2011. Retrieved August 1, 2012 from http://www.sciencewa.net.au/3520-wa-kronicles-synthetic-cannabinoid-detection.html and archived at: http://www.webcitation.org/64bFcL2hQ

Hughes, B., \& Winstock, A.R. (in press). Controlling new drugs under marketing regulations. Addiction.

Lietz, C. A. (2010). Evaluating qualitative research for social work practitioners. Advances in Social Work, 11, 188-202

Lindigkeit, R., Boehme, A., Eiserloh, I., Luebbecke, M., Wiggermann, M., Ernst, L., et al. (2009). Spice: A never ending story? Forensic Science International, 191, 58-63.

Macdonald K. (2011, April 13). Drug invisible to mine site tests. The West Australian. Retrieved August 1, 2012 from http://au.news.yahoo.com/thewest/a//newshome/9184524/drug-invisible-to-mine-site-tests/.

McArthur, M. (1999). Pushing the drug debate: The media's role in policy reform. Australian Journal of Social Issues, 34, 149-165.

Measham, F., Moore, K., Newcombe, R., \& Welch, Z. (2010). Tweaking, bombing, dabbing and stockpiling: The emergence of mephedrone and the perversity of prohibition. Drugs and Alcohol Today, 10(1), 14-21. doi: 10.5042/daat.2010.0123

Misuse of Drugs (Amounts of Prohibited Drugs) Order (No. 2) 2011, Western Australia. Statute on Internet. Available at: http://www.parliament.wa.gov.au/publications/tabledpapers.nsf/displaypaper/3813677 a4ad0d6610ca4ff4e482578e8001dac50/\$file/3677.pdf.

Misuse of Drugs Order 2011 (S.R. 2011, No. 74) - Reg 4, Tasmania.

Misuse of drugs amendment (synthetic cannabinoids) regulations 2011 (No 33 of 2011), Northern Territory. 
Morse, J. (1994). Designing funded qualitative research. In N. K. Denzin \& Y. S. Lincoln (Eds.), Handbook of qualitative research. Thousand Oaks, CA: Sage.

Office of the Associate Minister of Health. (2012). Regulation of psychoactive substances. Retrieved July31, 2012, from http://www.health.govt.nz/about-ministry/legislationand-regulation/regulatory-impact-statements/new-regulatory-regime-psychoactivesubstances

Pemberton, M. (2010, March). I took Mephedrone and I liked it. Retrieved November 28, 2012: http://www.telegraph.co.uk/health/7481469/I-took-mephedrone-and-I-likedit.html

Phillips Y. (2011, August 5). Kronic blamed for death as Government ban widens. Perth Now. Retrieved July 31, 2012: http://www.perthnow.com.au/news/hillman-man-38dies-after-smoking-kronic/story-e6frg12c-1226108817744

Poisons (Appendix A Amendment) Order (No. 2) 2011, Western Australia.

Psychonaut Web Mapping Research Group (2009). Spice report. Retrieved August 1, 2012 from http://www.psychonautproject.eu/documents/reports/Spice.pdf

Quartermaine, C., Tilley, T., Barrington, J., \& Kaitlyn, K. (Reporters). (2011, May 10). Cheating workplace drug tests. [Podcast radio programme].Sydney: ABC Triple J Radio. Retrieved May 11, 2011, from http://www.abc.net.au/triplej/hack/stories/s3212555.htm

Rickard, L. (2011, June 14). Kronic ban sparks 'fire-sale' fears. Retrieved from http://www.watoday.com.au/wa-news/kronic-ban-sparks-firesale-fears-201106131g06a.html\#ixzz1eUgKuARZ

Schifano, F., Corazza, O., Deluca, P., Davey, Z., Di Furia, L., Farre, M., et al. (2009). Psychoactive drug or mystical incense? Overview of the online available information on Spice products. International Journal of Culture and Mental Health, 2, 137-144.

Shanks, K. G., Dahn, T., Behonick, G., Terrell, A. (2012). Analysis of first and second generation legal highs for synthetic cannabinoids and synthetic stimulants by ultraperformance liquid chromatography and time of flight mass spectrometry. Journal of Analytical Toxicology, 36, 360-371. 
The Standard for the Uniform Scheduling of Medicines and Poisons (SUSMP) also known as the Poisons Standard 2011, Australia.

Therapeutic Goods Administration (TGA). (2011). Reasons for scheduling delegate's final decisions, July 2011. Canberra: Commonwealth of Australia.

Therapeutic Goods Administration (TGA). (2012). Final decisions and reasons for decisions by delegates of the secretary to the Department of Health and Ageing. Canberra: Commonwealth of Australia.

Tilley, T., \& Sawrey, K. (Reporters). (2011, July 7). National Kronic Ban. [Podcast radio programme].Sydney: ABC Triple J Radio. Retrieved May 11, 2011, from http://www.abc.net.au/triplej/hack/stories/s3263955.htm

Trans-Tasman Mutual Recognition (South Australia) Variation Regulations 2011, South Australia. 


\section{Tables}

Table 1. Description of the dominant AOD-related discourses in Australia, as reported by Bright et al. (2008).

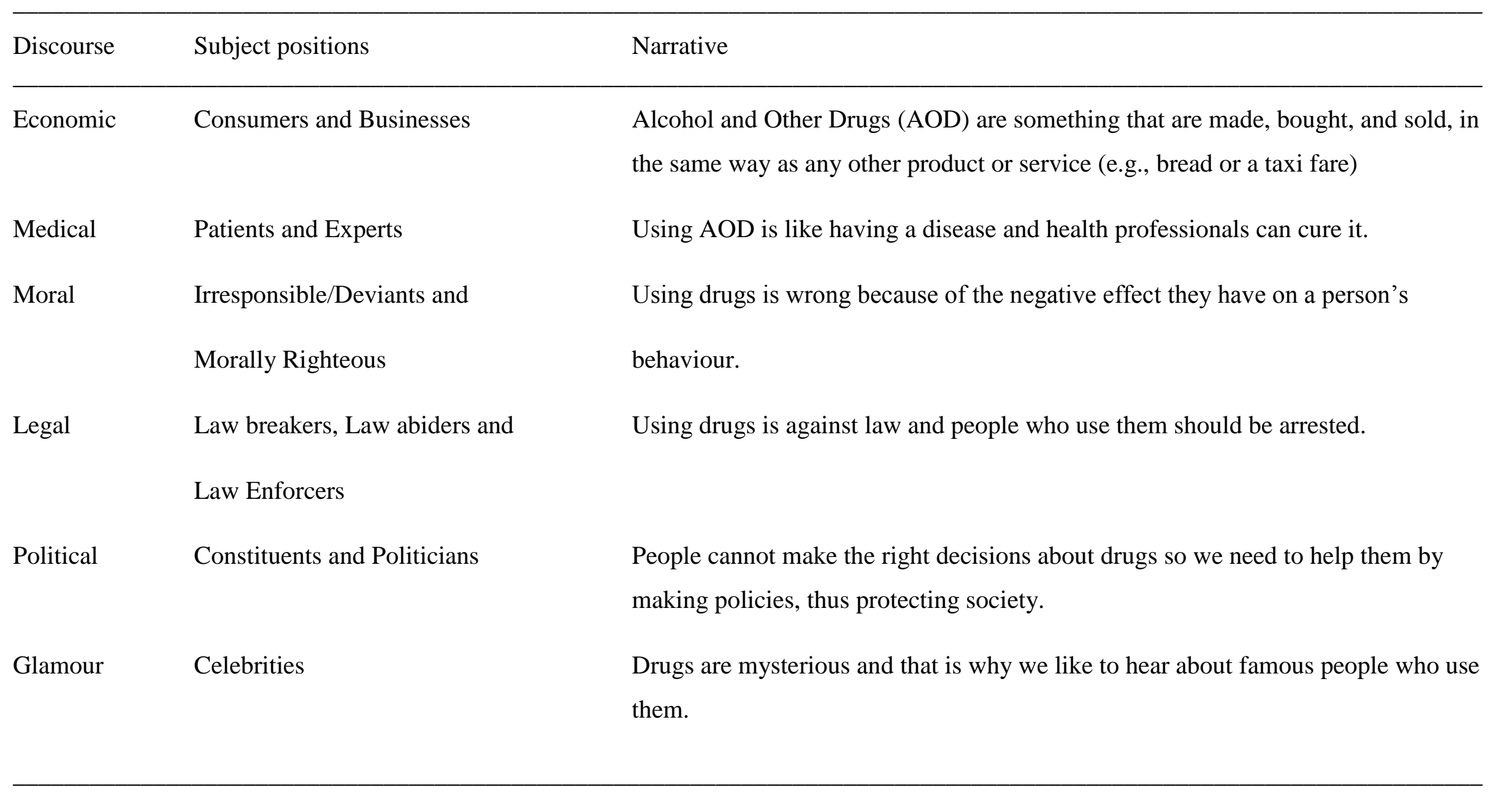




\section{Figures}

Figure 1. Google Trends data for 'Kronic' in Australia for 2011.

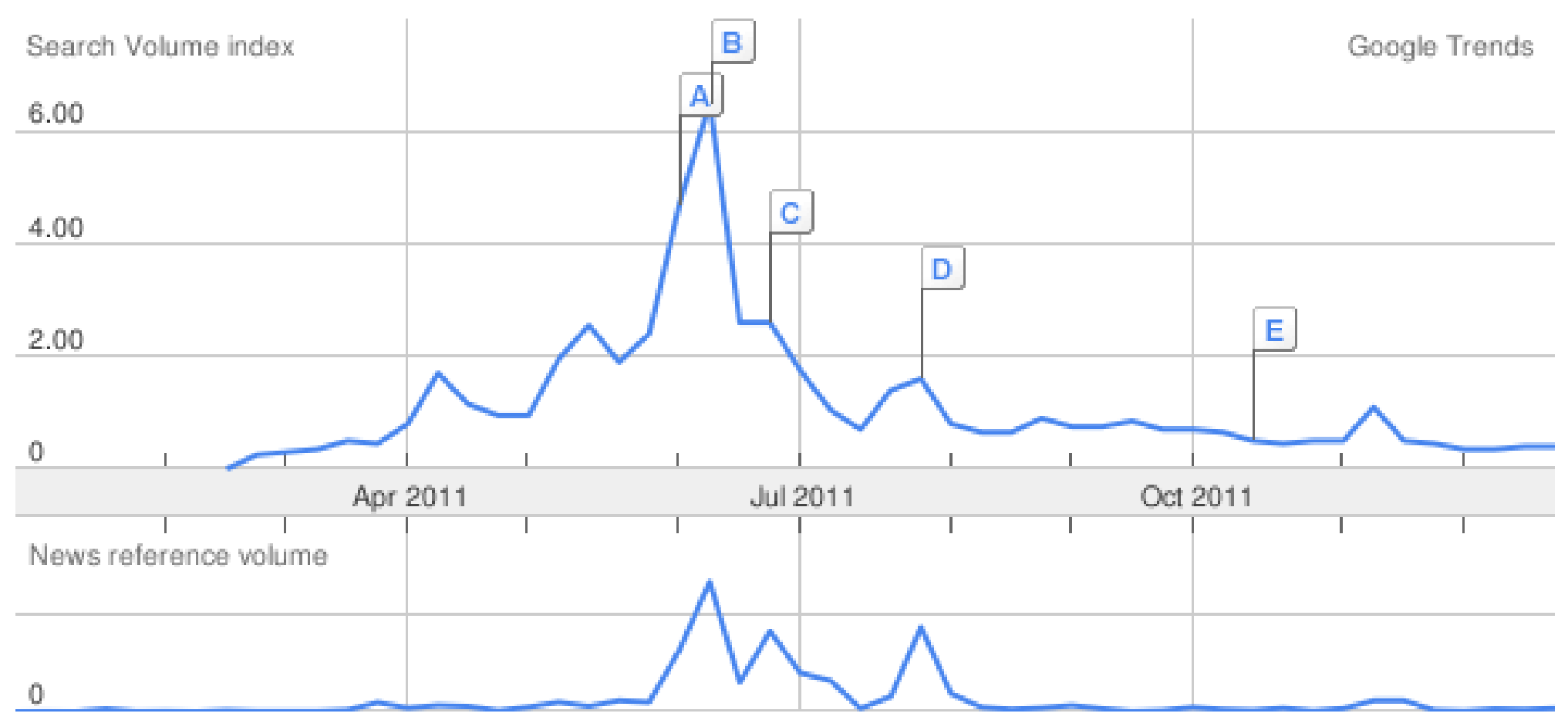

Note: The letters indicate the publication of key stories. The headlines for these are: (A) Roadtesting Kronic: Is fake grass worth the hype? (B) WA becomes first state with Kronic ban, (C) NZ importer admits Kronic contaminated, (D) WA Police query banned drug Kronic link to man's death, \& (E) Tall Black slapped with one-year ban for Kronic use. The lower line represents the volume of stories being published about Kronic and the upper line represents the number of searches for Kronic. 
Figure 2. Google Trends data for 'synthetic cannabis' in Australia for 2011.

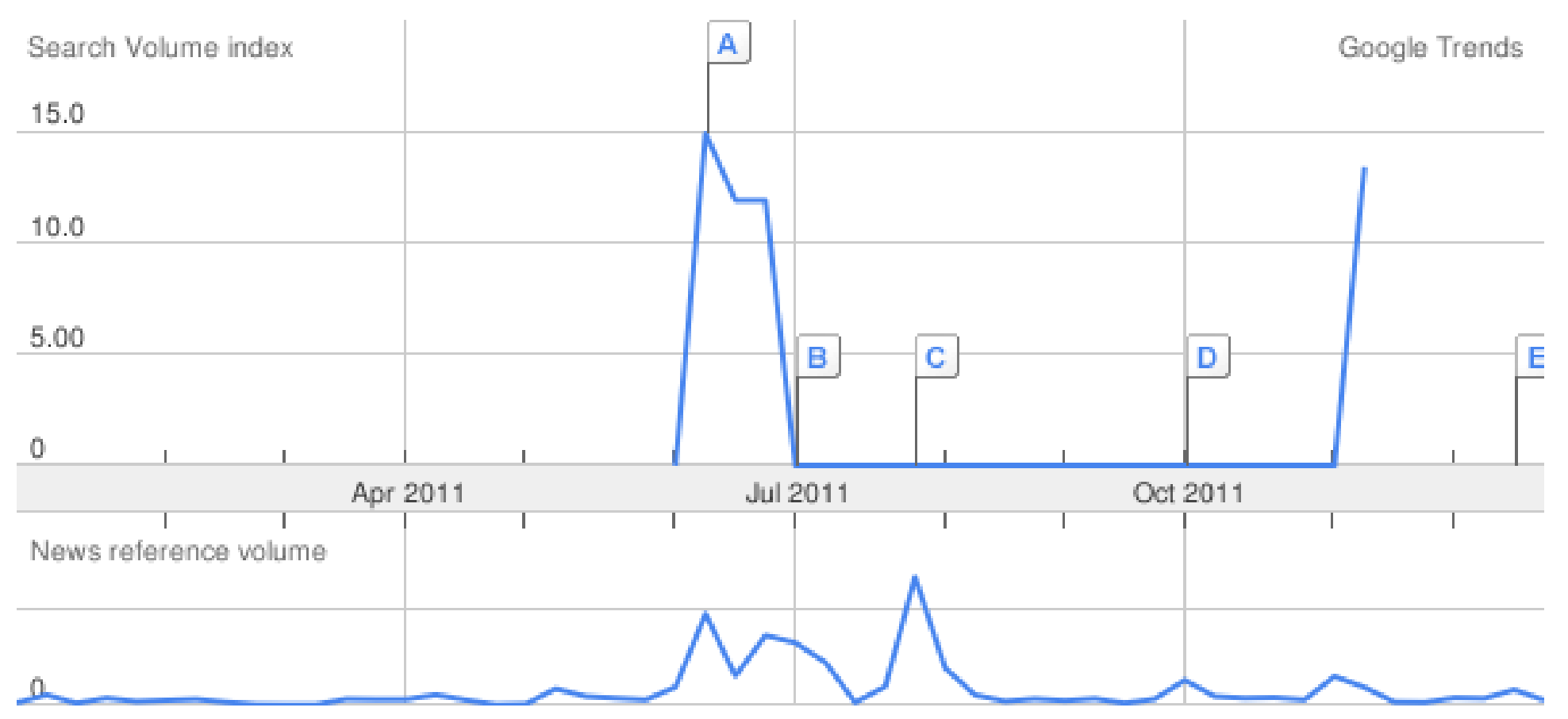

Note: The letters indicate the publication of key stories. Only story A was included in the analysis as the other stories were from New Zealand. The lower line represents the volume of stories being published about Kronic and the upper line represents the number of searches for Kronic. 
Figure 3. Month and year that participants from Barratt et al.'s (in press) survey respondents who reported first trying synthetic cannabis in 2011 versus the volume of Kronic and synthetic cannabis media reports, as indicated by Google Trends.

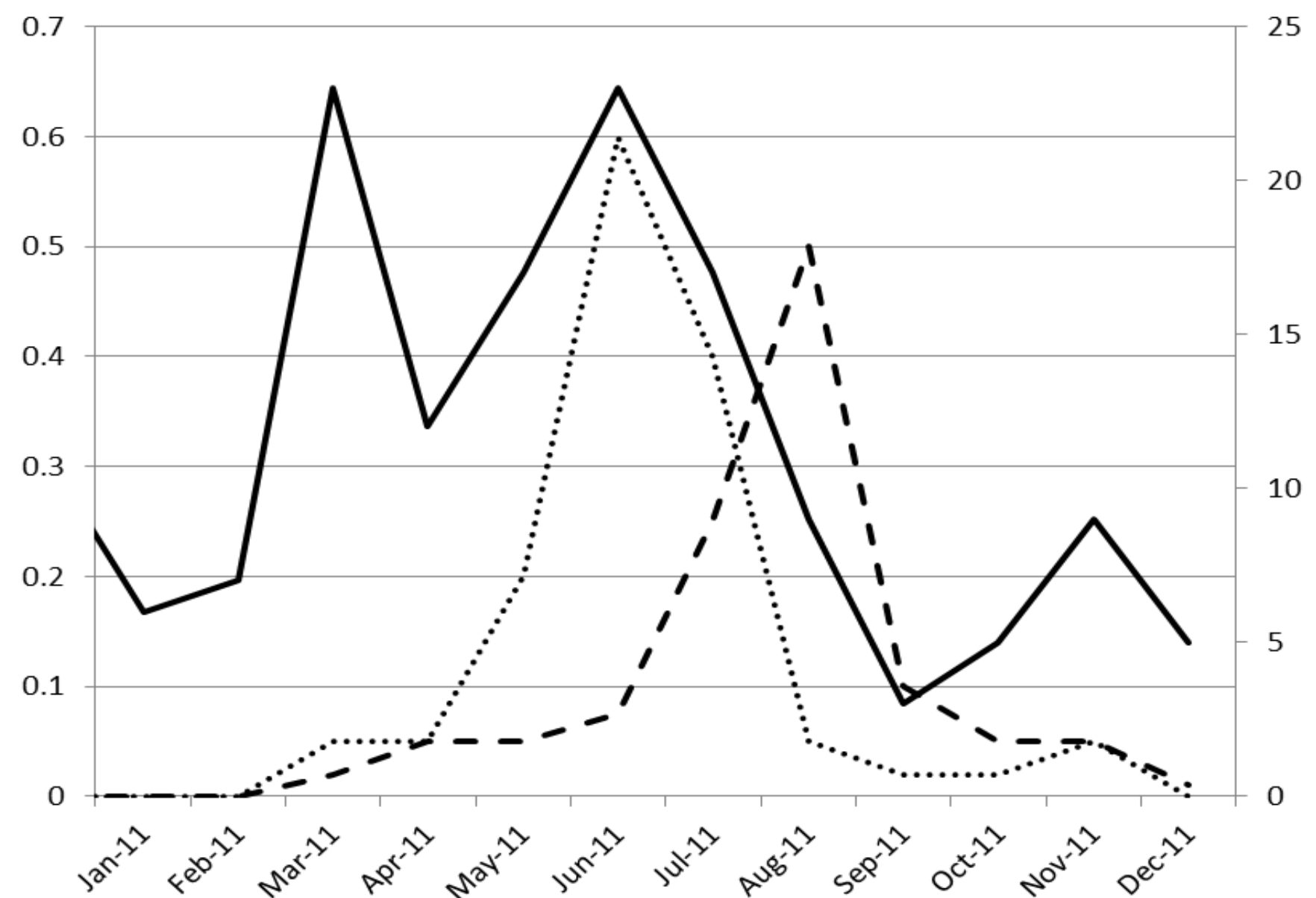

...... Volume of Kronic news

- Volume of synthetic cannabis news

N First tried synthetic cannabis

Note: As Google Trends does not provide raw data, the volume of media reports is only an approximation. Further, the data is normalised and does not represent the absolute number of media stories. 
${ }^{\star}$ Conflict of Interest Statement

This research comprises part of the first author's PhD. We have no conflicts of interests to declare. 